\title{
Addiction to 'Gul' and 'Gutkha' Leading to Acute Pulmonary Thrombosis and Acute Psychosis in a Young Pregnant Lady
}

\author{
Shridhar Dwivedi ${ }^{\mathrm{a}}$, Amitesh Aggarwala, b
}

\begin{abstract}
Gul is an oral tobacco powder which is rubbed over the gum and teeth. Being a tobacco preparation it is addictive in nature. It is popular among rural women in the south Asian countries. Not much is known about long term of gul on atherogenesis and/or pregnancy. Gul alone may or may not exert harmful effect on future course of pregnancy, however when combined with another tobacco preparation 'gutkha' which contains tobacco and betel nut, it may be dangerous for the foetus as well as for the mother. So far little has been reported regarding the atherogenic potential of gul and gutkha during pregnancy. We recently came across a young pregnant lady who was addicted to gul and gutkha for long. She developed acute pulmonary thrombosis during 32nd week of pregnancy and had previous two episodes of abortions. Her thrombophilic profile was normal. The pulmonary thrombosis resolved after preterm delivery and anticoagulant therapy. However, she developed acute craving for gul and gutkha and acute psychosis on 5th day of delivery which responded to antipsychotic regimen. Present case highlights the highly addictive and potentially atherogenic effects of gul, considered innocuous by users. The case focuses the catastrophic effect of gul and gutkha which may lead to thrombophilic state when taken during pregnancy.
\end{abstract}

Keywords: Gul; Gutkha; Pulmonary thrombosis; Pregnant

\section{Introduction}

Smoking is well known for its harmful effect on continu-

Manuscript accepted for publication July 14, 2010

${ }^{a}$ Department of Medicine/Preventive Cardiology, University

College of Medical Sciences, University of Delhi and GTB Hospital,

Delhi-110095, India

${ }^{\mathrm{b}}$ Corresponding author: dramitesh@gmail.com

doi: $10.4021 / \mathrm{jmc} 7 \mathrm{w}$ ance of pregnancy and on foetal health. It is also known to precipitate acute thrombosis in susceptible individuals [1]. However, not much has been reported regarding the atherogenic potential of 'gul' and 'gutkha' when taken together or gul alone. Gul is an oral tobacco powder which is rubbed over the gum and teeth [2]. Being a tobacco preparation, it is addictive in nature. It is popular among rural population in the south Asian countries. Gul alone may or may not exert harmful effect on future course of pregnancy, however when combined with another tobacco preparation 'gutkha' which contains tobacco and betel nut, it may be dangerous for the foetus as well as for the mother.

\section{Case Report}

We recently came across a young 30 -year-old pregnant lady, non diabetic and non hypertensive, a health care provider herself, who was addicted to gul and gutkha for last 18 years and developed acute pulmonary thrombosis during her $\underline{32 n d}$ week of pregnancy. She was also found to have bilateral extensive oral leukoplakia and trismus. Her thrombophilic profile was normal. There was no sonographic evidence of deep vein thrombosis either. The pulmonary thrombosis resolved after preterm delivery and anticoagulant therapy. However, she developed acute craving for gul and gutkha and subsequent psychosis on 5th day of delivery which responded to antipsychotic regimen.

\section{Discussion}

Present case highlights the highly addictive and potentially atherogenic effects of gul, considered innocuous by user population. The case focuses the catastrophic effect of gul and gutkha when taken during pregnancy leading to thrombophilic state and pulmonary embolism. The possible role of gul and gutkha in previous abortions and preterm labour cannot be overlooked. Recent data from Bangladesh showed that gul usage is $1.8 \%$ of tobacco consuming sample. Application of gul was reported most frequently $(5.2 \%)$ by urban women of lower socioeconomic classes [3]. Among rick- 
shaw pullers, $42.7 \%$ reported applying gul and $45 \%$ used betel quid with tobacco [4]. Another case report from Germany highlighted the occurrence of early onset oral submucous fibrosis in a 31-year-old woman addicted to pan masala and gutkha since 17 years of age [5]. There is a general misconception that smokeless tobacco consumption in any form is considered relatively harmless by consumers despite ample evidence to the contrary. Chronic use of smokeless tobacco consumption is associated with increasing prevalence of early onset (age $\leq 40$ year) submucous fibrosis, leukoplakia and oral cancers, and tendency to develop diabetes, hypertension and coronary artery disease later [6]. It is prudent to record history of taking smokeless products like gul and gutkha as an integral part of clinical history. Further, stringent regulations need be framed and followed up against production and sale of gul and gutkha in South Asian countries.

\section{References}

1. Davis JW, Davis RF. Acute effect of tobacco cigarette smoking on the platelet aggregate ratio. Am J Med Sci 1979;278(2):139-143.

2. Puttaiah R, Carley K, Holavanahalli R. Tobacco, betel quid-quid chewing and oral health. In: Bedi R, Jones $\mathrm{P}$, eds. Betel quid-quid chewing and tobacco chewing among the Bangladeshi community in the United Kingdom. London, UK: Centre for Transcultural Oral Health 1995: 1-9.

3. Flora MS, Mascie-Taylor CG, Rahman M. Gender and locality differences in tobacco prevalence among adult Bangladeshis. Tob Control 2009;18(6):445-450.

4. World Health Organization, Bangladesh. Tobacco control among Rickshaw pullers. Dhaka: WHO, Bangladesh 2004.

5. Reichart PA, Philipsen HP. [Oral submucous fibrosis in a 31-year-old Indian women: first case report from Germany]. Mund Kiefer Gesichtschir 2006;10(3):192-196.

6. Nair U, Bartsch H, Nair J. Alert for an epidemic of oral cancer due to use of the betel quid substitutes gutkha and pan masala: a review of agents and causative mechanisms. Mutagenesis 2004;19(4):251-262. 